\title{
Characterizing Spatiotemporal Variations of Soil Salinization and Its Relationship with Eco-Hydrological Parameters at the Regional Scale in the Kashi Area of Xinjiang, China from 2000 to 2017
}

\author{
Bo Wang ${ }^{1}$, Xinguang Dong ${ }^{1, *}$, Zhihui Wang ${ }^{2,3, * \mathbb{D}}$ and Guoqiang Qin ${ }^{1}$ \\ 1 College of Hydraulic and Civil Engineering, Xinjiang Agricultural University, Urumqi 830052, China; \\ wangbojiashi@126.com (B.W.); qinguoqiang1988@163.com (G.Q.) \\ 2 Yellow River Institute of Hydraulic Research, Yellow River Conservancy Commission, \\ Zhengzhou 450003, China \\ 3 Key Laboratory of Soil and Water Conservation on the Loess Plateau of Ministry of Water Resources, \\ Zhengzhou 450003, China \\ * Correspondence: xinguangdong@163.com (X.D.); wangzhihui@hky.grcc.gov.cn (Z.W.)
}

check for updates

Citation: Wang, B.; Dong, X.; Wang, Z.; Qin, G. Characterizing Spatiotemporal Variations of Soil Salinization and Its Relationship with Eco-Hydrological Parameters at the Regional Scale in the Kashi Area of Xinjiang, China from 2000 to 2017. Water 2021, 13, 1075. https:// doi.org/10.3390/w13081075

Academic Editor: Maria Mimikou

Received: 11 March 2021

Accepted: 9 April 2021

Published: 14 April 2021

Publisher's Note: MDPI stays neutral with regard to jurisdictional claims in published maps and institutional affiliations.

Copyright: (C) 2021 by the authors Licensee MDPI, Basel, Switzerland. This article is an open access article distributed under the terms and conditions of the Creative Commons Attribution (CC BY) license (https:// creativecommons.org/licenses/by/ $4.0 /)$.

\begin{abstract}
Soil salinization is one of the most serious issues of land degradation, especially in inland drylands, such as the Kashgar region in the Xinjiang province, western China. The investigation of the spatiotemporal variations of soil salinization and its causes is critical for regional ecological restoration and social development. In this study, salinization severity was firstly interpreted in Kashgar region for the years 2000, 2010, and 2017 using multitemporal Landsat images, and the spatiotemporal variations of salinized soil area, salinization severity index, and important index of salinization change were then analyzed using transition matrix method. Finally, the relationship between salinization and eco-hydrological parameters at the regional scale was investigated using correlation analysis and multivariate linear regression. The results show that salinized soil is mainly concentrated in irrigated oasis areas. Although the decrease rate of total salinized soil area is decreasing, the decrease rate of average salinization severity is increasing gradually. There is an increasing trend for the improved area of salinized soil, whereas an opposite trend was observed for the deteriorated area of salinized soil. The conversion from extremely severe salinized soil to the severe ones was the dominant transforming type from 2000 to 2017; meanwhile, the transformation from non-salinized soil to salinized soil for the newly reclaimed farmland was observed, indicating that some necessary irrigation control measures must be taken to avoid further soil salinizing. A significant negative correlation between salinization severity and evapotranspiration, normalized difference vegetation index (NDVI) was observed, implying that soil structure change induced by vegetation, associated with high evapotranspiration (ET) and low land surface temperature (LST), played a positive role in alleviating soil salinization in this region. It is concluded that the soil salinization had been alleviated from 2000 to 2017, mainly due to the combined effects of the farmland expansion and the reasonable irrigation system.
\end{abstract}

Keywords: soil salinization; eco-hydrological factors; remote sensing; spatiotemporal patterns; correlation analysis

\section{Introduction}

Soil salinization is one of the severest land desertification and land degradation types around the globe [1], limiting the growth of crops, restricting food production and economic and social development [2], and greatly threatening the stability of regional ecology and the achievement of sustainable development goals (SDGs). More and more attention was being put to soil salinization studies around the globe, especially in inland drylands, mainly due 
to the increasing environmental pressures in these regions caused by climate change and the low-degree social developments [3-5].

About 36 million hectares of land are faced with soil salinization, taking about $6.62 \%$ of total cultivated land in China [6], threatening food production and ecological sustainability, especially in the inland dryland areas. The Xinjiang province in northwestern China is the most important reserved land for cultivated land resources in China. However, in this region, soil salinization caused by the combination of topography, climate, natural conditions of water and soil, and unreasonable exploitation and use by human beings are threatening the sustainability of ecology and social economy. According to the second National Soil Survey, the total area of salinized land in Xinjiang was 13.36 million hectares, accounting for $36.8 \%$ of the salinized land in China [7]. The Kashgar region, located on the southwest edge of the Taklamakan Desert, is one of the most important agricultural product bases in Xinjiang. However, the Kashgar region is faced with serious soil salinization, with more than half of the cultivated land are experiencing soil salinization [8], seriously affecting the sustainable development of local ecology, economy, and society. Therefore, investigating the spatial and temporal evolution and its attributions of soil salinization can provide the theoretical basis and scientific support for the policy-making of land resources protection and for the scientific planning and use of the land resources in the Kashgar region [9].

The traditional field-based methods can provide accurate soil salt content, but this is really expensive and time-consuming; moreover, it is impossible to obtain the spatially continuous data for the salinized soil by these field-based methods. With the rapid development of remote sensing technology, some new approaches have been reported for the dynamic monitoring of soil salinization at the regional scale. For example, a large number of studies have established soil salt content inversion model based on spectral characteristics [10] and its dynamic phenological metrics derived from remote sensing data such as Landsat [11-14], Sentinel-2A [15], medium-resolution image spectrometer (MODIS) [16,17], and airborne hyperspectral data [18]. However, soil cannot be directly observed by satellite sensors when there is a dense vegetation canopy that covers the underlying soil [19]. To solve these problems, some key factors that affect the formation of salinized soil were considered, such as terrain factors, vegetation, and hydrological parameters to improve the inversion accuracy of soil salinization $[19,20]$. The inversion methods have also evolved from the simple linear regression model to complicated geostatistical spatial interpolation models [21-23], artificial intelligence, or machine learning models [19], which greatly improved the regional study of soil salinization.

It is well-recognized that soil salinization was the combined result of both natural environment and intense human activities [24]. The influencing natural factors mainly include climate factors, terrains, soil types, vegetation covers, and hydrological conditions. For example, extreme climatic conditions, including extreme drought [25], high temperature [24], and severe potential evapotranspiration [6] will lead to excessive loss of soil water and rapid accumulation of soil salt. The terrain conditions can cause the spatial differentiation of soil salinization by affecting surface and underground runoff $[26,27]$. Soil type is also one of the important factors affecting salinization because the soil structure influences its hydraulic properties and further affects the movement of soil water and salt [24,28]. Vegetation coverage [6] and hydrological conditions [29,30] are also significant factors influencing soil water and salt content. Human activities, including land use conversions [31], cultivating expansion and vegetation restoration [6], and groundwater exploitation [27], are also important factors contributing to the formation and the spatiotemporal patterns of soil salinization.

At present, most studies relating to the attribution and detection of soil salinization mainly focused on field-based investigations. Thus, the impacts of environmental factors, such as eco-hydrological drivers (such as vegetation cover, evapotranspiration, and groundwater level.) on the spatiotemporal evolution of salinization are still unclear, especially at the regional scale, due to the mismatch between the point-scale of field measured data and 
the large-scale of remotely-sensed eco-hydrological parameters. Meanwhile, the bridge role of medium-resolution remote sensing data was also usually ignored for soil salinization studies because of the lack of severity index of salinization at the regional scale. Thus, the objectives of this study are to (1) detect the spatiotemporal variation of soil salinization at regional scale in the Kashgar based on interpretation from Landsat images; (2) propose a soil salinity severity index at regional scale by the combination of salinization severity and its area; and (3) explore the potential relationship between soil salinity and eco-hydrological factors at regional scale in the Kashgar. This study can provide new techniques for accurate detection and attribution of spatiotemporal variation of soil salinization at the regional scale.

\section{Materials and Methods}

\subsection{Study Area}

Kashgar region is located in the southwest of Xinjiang Uygur autonomous region of China, with a geographical extent of $73^{\circ} 20^{\prime} \sim 79^{\circ} 57^{\prime} \mathrm{E}$ and $35^{\circ} 20^{\prime} \sim 40^{\circ} 18^{\prime} \mathrm{N}$ (Figure 1). The region has jurisdiction over one county-level city, 10 counties, and one autonomous county, with a total area of $1.28 \times 10^{5} \mathrm{~km}^{2}$ [32]. Kashgar region belongs to the warm temperate continental arid climate zone where experience four clearly distinct seasons and long illumination time. Annual precipitation and the average temperature in this region are $62.5 \mathrm{~mm}$ and $12{ }^{\circ} \mathrm{C}$, respectively. It has a large annual potential evapotranspiration with a magnitude of $2100 \mathrm{~mm}$. Yeerqiang River and Kashgar River are the main rivers in the Kashgar region where the average annual runoff volume is 12 billion $\mathrm{m}^{3}$, and the flood period is from Jun. to Sep. The two oases along these two main rivers are important agricultural production areas in Xinjiang Uygur autonomous region. The land cover types in the Kashgar region include desert, cropland, and grassland. Crops are mainly located at the two major oases, and natural vegetation includes alpine meadow, swamp vegetation, and desert vegetation, and forest coverage is only $2.75 \%$. There are more than ten soil types in this region, including subalpine steppe soil, oasis soil, brown calcic soil, brown desert soil, marshy soil, saline soil, etc. Moreover, piedmont clinoplain is the typical hydrogeological characteristic. A large amount of salt accumulates along the surface runoff or underground runoff to the alluvial fan plain zone that has poor drainage from the exposed tertiary stratum around the basin margin.

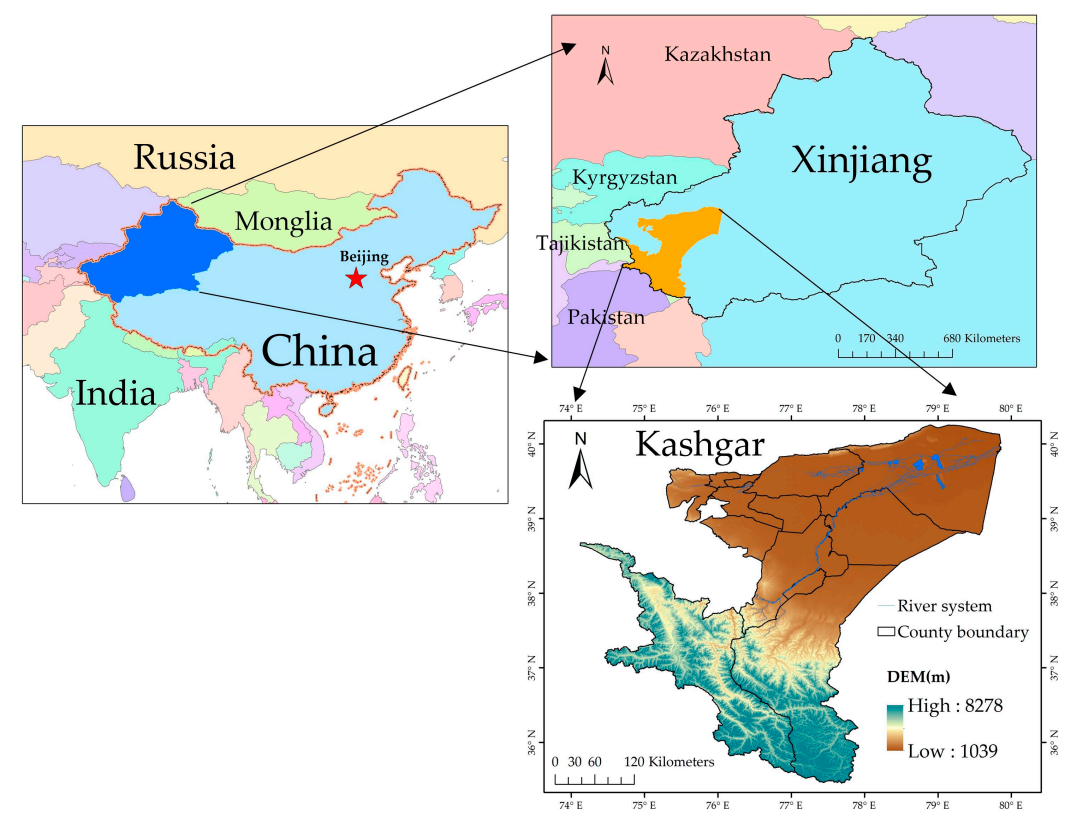

Figure 1. Geographic location of the study area. 


\subsection{Data and Preprocessing}

We used Landsat5 TM, Landsat7 ETM+, and Landsat8 OLI satellite data with a spatial resolution of $30 \times 30 \mathrm{~m} \mathrm{[33]} \mathrm{as} \mathrm{the} \mathrm{land} \mathrm{surface} \mathrm{reflectance} \mathrm{data} \mathrm{sources} \mathrm{for} \mathrm{the} \mathrm{remote}$ sensing interpretation of soil salinization. The Landsat images (Path: 146 150, Row: 32 35) cover the whole study area with a total number of 18 scenes for each year. Satellite images in three periods of 1999 to 2000, 2009 to 2011, and 2017 were selected to acquire the soil salinization information during the past two decades. The normalized difference vegetation index (NDVI) and land surface temperature (LST) were derived from the medium-resolution image spectrometer (MODIS) products [34]. Total water storage anomalies (TWSA) were generated from the grace gravity satellite mascon products, which were provided by the American Space Research Center (CSR) and the American Jet Dynamics Laboratory (JPL) [35]. Soil moisture (SM) and evapotranspiration (ET) were generated from the Global Land Data Assimilation System (GLDAS) that was driven by three land surface models (i.e., Noah, VIC, and CLSM) [36], the Global Land Evaporation Amsterdam Model (GLEAM) products developed by the European Space Agency (ESA) [37], and PML_V2 products that were provided by the Australian Commonwealth Scientific and Research Organization (CSIRO) [38]. The time range, spatial resolution, and temporal resolution of all remote sensing products were shown in Table 1. Other auxiliary data include a topographic map with a scale of 1:100,000, county population, gross domestic product (GDP), and other socio-economic data.The Landsat images covering the study area contain 18 remote sensing data for each year, and the middle image in space was selected as the reference image for geometric correction in each period based on the overlapping area. After mosaic, the 1:100,000 topographic map was used as the reference image for further geometric correction. A total of 40 control points were selected for each scene during the registration, and the bias was controlled within half a pixel. In order to reduce the uncertainty of different water cycle parameter products (i.e., TWSA, SM, and ET), we conducted a fusion processing among the gravity recovery and climate experiment (GRACE) products, four soil moisture products, and five evapotranspiration products, separately. Finally, the annual SM, ET, NDVI, LST data sets from 2000 to 2018 and annual TWSA data sets from 2003 to 2018 were obtained based on the annual accumulation or average algorithms.

Table 1. Remote sensing products of eco-hydrological parameters used in this study.

\begin{tabular}{ccccc}
\hline Parameters & Products & Time Range & $\begin{array}{c}\text { Spatial } \\
\text { Resolution }\end{array}$ & $\begin{array}{c}\text { Temporal } \\
\text { Resolution }\end{array}$ \\
\hline $\begin{array}{c}\text { Land surface } \\
\text { reflectance }\end{array}$ & Landsat TM & $\begin{array}{c}\text { July-September, } \\
\text { 2009-2011 } \\
\text { July-September, }\end{array}$ & $30 \mathrm{~m}$ & - \\
& Landsat ETM+ & 1999-2000 & $30 \mathrm{~m}$ & - \\
\hline NDVI & Landsat OLI & July-September, 2017 & $30 \mathrm{~m}$ & - \\
\hline \multirow{2}{*}{ TWSA } & MODIS & $2000-2018$ & $500 \mathrm{~m}$ & 16 days \\
& GRACE CSR Mascon & $2003-2018$ & $0.25^{\circ}$ & Monthly \\
\hline \multirow{2}{*}{ SM } & GRACE JPL Mascon & $2003-2018$ & $0.25^{\circ}$ & \\
& GLDAS_Noah & $2000-2018$ & $0.25^{\circ}$ & Monthly \\
& GLDAS_VIC & $2000-2018$ & $1^{\circ}$ & \\
\hline \multirow{2}{*}{ ET } & GLDAS_CLSM & $2000-2018$ & $1^{\circ}$ & \\
& GLEAM & $2000-2018$ & $0.25^{\circ}$ & Monthly \\
& GLDAS_Noah & $2000-2018$ & $0.25^{\circ}$ & $1^{\circ}$ \\
& GLDAS_VIC & $2000-2018$ & $1^{\circ}$ & 8 days \\
\hline LST & GLDAS_CLSM & $2000-2018$ & $0.25^{\circ}$ & 8 days \\
\hline
\end{tabular}




\subsection{Soil Salinization Severity Interpretation Based On Remote Sensing Data}

According to the classification criteria of desertification type and severity in Xinjiang Uygur autonomous region in Atlas of sandy desertification land in China, published by the State Forestry Administration, P. R. China [39], the salinized soil in the Kashgar region was divided into five grades: non-salinized soil, slightly salinized soil, moderately salinized soil, severely salinized soil, and extremely severely salinized soil. The extraction methods of soil salinization based on remote sensing data are organized as follows:

(1) We firstly selected salinized soil samples under the five soil salinization grades from Landsat images in different periods based on the field survey records and further divided the selected samples into the training samples $(70 \%)$ and validation samples $(30 \%)$.

(2) We established the soil salinization interpretation rules (Table 2, Figure 2) according to the color, shape, texture, spatial distribution characteristics in the Landsat images of the field survey. We select the optimal band combination of different Landsat satellite images by comparing the visual interpretation effects from different band combinations.

(3) Combined with the 1:100,000 topographic map, groundwater depth, land surface albedo, vegetation type and coverage, and other prior knowledge, we used random forest and artificial visual interpretation methods to identify different levels of soil salinization severity. Finally, we developed three accurate soil salinization thematic maps for 2000, 2010, and 2017 with a spatial resolution of $30 \times 30 \mathrm{~m}$.

Table 2. Visual interpretation rules for the soil salinization classification based on Landsat images.

\begin{tabular}{|c|c|c|}
\hline Categories & Distribution Characteristics & Artificial Visual Interpretation Rules \\
\hline $\begin{array}{c}\text { Slightly } \\
\text { salinized soil }\end{array}$ & $\begin{array}{l}\text { Located in the upstream of Kashgar River } \\
\text { Basin and Yarkand River Basin, where plants } \\
\text { are all agricultural vegetation with low } \\
\text { salinization severity and high } \\
\text { vegetation coverage. }\end{array}$ & $\begin{array}{l}\text { Crop growth is slightly inhibited, } \\
\text { with } 1 / 10-1 / 3 \text { of the area being bare, } \\
\text { showing light green color and slightly } \\
\text { heterogeneous hue in the images. A small } \\
\text { amount of white or light gray bright spots } \\
\text { are mixed in the green plot in the images, } \\
\text { accounting for } 5-10 \% \text { of the whole image. }\end{array}$ \\
\hline Moderately salinized soil & $\begin{array}{l}\text { Located in the lower reaches of the slightly } \\
\text { salinized soil regions, and there is a small } \\
\text { range of severe salinization area around, where } \\
\text { plants are mainly agricultural vegetation. } \\
\text { However, the vegetation coverage is lower } \\
\text { than that in the slightly salinized regions. } \\
\text { The crop types are quite different from those in } \\
\text { the slightly salinized regions. The inner plots } \\
\text { are mainly smooth and bright in images. }\end{array}$ & $\begin{array}{c}\text { Crop growth is moderately inhibited, } \\
\text { with } 1 / 3-1 / 2 \text { of the area being bare. Uneven } \\
\text { spots with green or light green color are } \\
\text { usually shown in images. Light tone and } \\
\text { white spots are mixed, accounting for } \\
10 \%-25 \% \text { of the whole image. }\end{array}$ \\
\hline Severely salinized soil & $\begin{array}{l}\text { Located in the lower reaches with low terrain, } \\
\text { where plants are mainly agricultural } \\
\text { vegetation. The vegetation coverage is similar } \\
\text { to that in the moderately salinized regions. } \\
\text { There usually is a higher proportion of smooth } \\
\text { spots with high brightness in the images. }\end{array}$ & $\begin{array}{l}\text { Crop growth is severely inhibited, with more } \\
\text { than half of the area being bare. Uneven } \\
\text { polygons with light green, uneven texture, } \\
\text { and rough texture are usually shown in } \\
\text { images. White and grayish-white patches are } \\
\text { mixed in green patches, accounting for more } \\
\text { than } 50 \%-70 \% \text { of the whole image. }\end{array}$ \\
\hline
\end{tabular}

It is widely distributed in the lower reaches of Kashgar River Basin, Gaizi River Basin, and Yeerqiang River Basin, where they have more water content. The vegetation type is mainly natural vegetation. The image color of the waterlogged area is mainly black gray, grayish brown, and tan with a dark hue. Image colors of the water-free area that close to the desert are mainly light white, gray-white with
Crop growth is seriously inhibited, with more than $2 / 3$ of the area being bare. The texture of the image is uneven and rough. White and grayish-white patches are mixed in green patches, accounting for more than $70 \%$ of the whole image. 

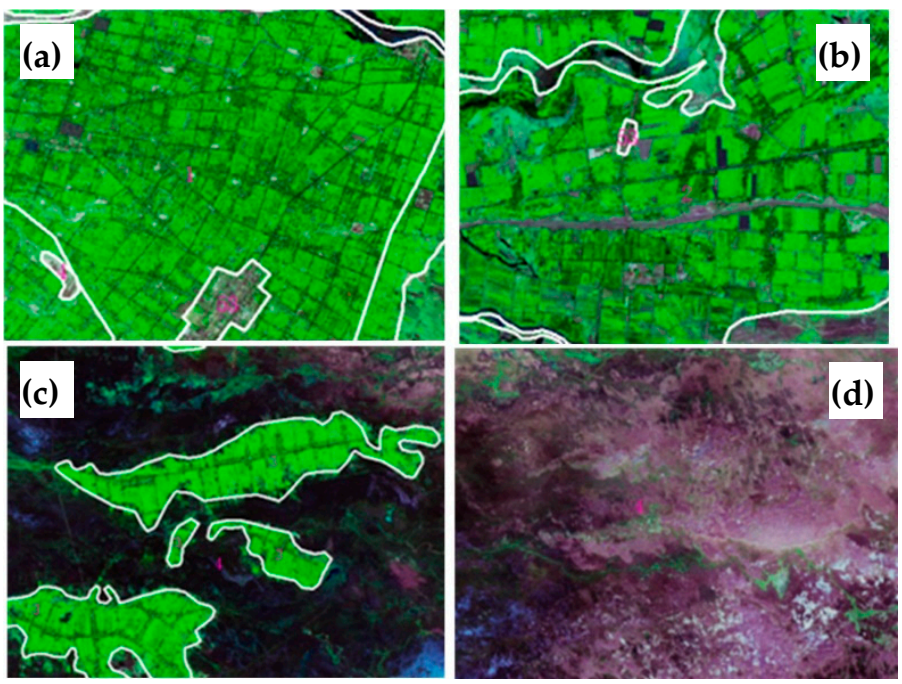

Figure 2. The soil salinization interpretation reference database for different salinized soil grades. Sub-figure (a-d) represent slightly salinized soil, moderately salinized soil, severely salinized soil, and extremely severely salinized soil, respectively.

\subsection{Soil Salinization Dynamics Description Based on Transition Matrix}

Based on the soil salinization database of the three periods, we analyzed the area and direction of mutual transformation among different salinized soil types using the transition matrix [40], which can be expressed as follow:

$$
S_{i j}=\left|\begin{array}{cccc}
S_{11} & S_{12} & \cdots & S_{1 n} \\
S_{21} & S_{22} & \cdots & S_{2 n} \\
\vdots & \vdots & \vdots & \vdots \\
S_{n 1} & S_{n 2} & \cdots & S_{n n}
\end{array}\right|
$$

where $S_{i j}$ is the transferred area from salinized soil type $i$ to type $j$ in the study period; $i$ is the type of salinized soil in the previous period, $\mathrm{j}$ is that in the later period, and $\mathrm{n}$ is the total number of salinized soil types.

In this paper, salinized soil area and salinization severity index are used to describe the spatial and temporal distribution characteristics of the regional soil salinization:

$$
S=\sum_{i=1}^{4} \frac{A_{i}}{A} \times P_{i}
$$

where, $S$ is the regional soil salinization severity index, $A_{i}$ is the area $\left(\mathrm{km}^{2}\right)$ of salinized soil type $i, A$ is the total area $\left(\mathrm{km}^{2}\right)$ of the study area, $P_{i}$ is the weight of salinized soil type $i$. The weights of slightly salinized soil, moderately salinized soil, severely salinized soil, and extremely severely salinized soil are 1,2,3, and 4, respectively. The larger S represents the more severe soil salinization in a specific region.

$$
P A=\frac{A_{t 2}-A_{t 1}}{A_{t 1}} \times 100 \%
$$

where $P A$ is the relative change rate of the total area of salinized soil, which indicates the change degree of the area of salinized soil. The larger $P A$ means a greater change of the total area of salinized soil in the specific region. $A_{t 2}$ is the total area of salinized soil at time $t_{2}$, and $A_{t 1}$ is the total area of salinized soil at time $t_{1}$.

$$
P S=\frac{S_{t 2}-S_{t 1}}{S_{t 1}} \times 100 \%
$$


where $P S$ is the relative change rate of soil salinization severity, which indicates the change percentage of soil salinization severity. A larger PS represents a larger change of the soil salinization condition in the specific region. $S_{t 2}$ is the salinization severity at time $t_{2}$, and $S_{t 1}$ is that at time $t_{1}$.

In this study, the importance index of soil salinization change $\left(C I_{i}\right)$ [41] was used to screen out the main change types of the salinized soil in different periods. The calculation formula of $C I_{i}$ is shown in Equation (5):

$$
C I_{i}=\frac{C A_{i}}{\sum_{i}^{n} C A_{i}} \times 100 \%
$$

where $C I_{i}$ represents the importance of the change area of the $\mathrm{i}_{\text {th }}$ salinized soil type in the whole changed soil salinization area in the specific region, and the range of $C I_{i}$ is from 0 to $100 \% ; C A_{i}$ is the change area of the $i_{\text {th }}$ salinized soil type $\left(\mathrm{km}^{2}\right) ; \sum_{i}^{n} C A_{i}$ is the total area of all changed salinized soil types in the region $\left(\mathrm{km}^{2}\right)$; and $\mathrm{n}$ is the number of all changed types.

The larger the $C I_{i}$ means that the change of one specific type of soil salinization takes a larger percentage of the whole changed area for all five grades. Considering that there are many kinds of land-use changes, the $C A_{i}$ values are arranged in descending order from large to small, and the salinized soil types whose cumulative $C A_{i}$ values are more than $75 \%$ are statistically mapped to highlight the main change types of salinized soil in this area.

\subsection{Mann-Kendall Nonparametric Test}

In this paper, the temporal variation of key eco-hydrological factors that may affect the process of soil salinization was analyzed based on the Mann-Kendall test method [42-47], including NDVI, soil moisture, terrestrial water storage anomaly, land surface temperature, and evapotranspiration.

\subsection{Relationship between Soil Salinization to Eco-Hydrological Parameters}

In this study, the spatial resolution of all the eco-hydrological parameters and the newly extracted soil salinization maps are different; thus, the soil salinization classification maps were divided into a resolution of $0.25^{\circ} \times 0.25^{\circ}$, to match the spatial scales of remote sensing products of different eco-hydrological parameters, and then the salinization severity and salinized soil area in each grid were calculated. We further calculated the changes of soil salinization severity and salinized soil area in each grid from 2000 to 2017 and extracted the corresponding change eco-hydrological parameters including NDVI, LST, ET, soil moisture (SM), and TWSA. The correlations between soil salinization index and each eco-hydrological parameter were analyzed using the single linear regression method.

$$
r=\frac{\sum_{i=1}^{n}\left(X_{i}-\bar{X}\right)\left(Y_{i}-\bar{Y}\right)}{\sqrt{\sum_{i=1}^{n}\left(X_{i}-\bar{X}\right)^{2}} \sqrt{\sum_{i=1}^{n}\left(Y_{i}-\bar{Y}\right)^{2}}}
$$

The multiple linear stepwise regression method was used to establish the quantitative response relationships between soil salinization characteristic index and eco-hydrological parameters. In this method, all the eco-hydrological parameters were introduced into the model one by one. After each new variable was introduced, F-test was carried out, and a t-test was further carried out on the original variables one by one. Thus, the insignificant eco-hydrological parameters were deleted based on the t-test and F-test. After the test of all the independent variables, the most robust fitting equation constructed by the optimal independent variables was obtained. The regression model is shown as follow:

$$
\Delta Y=\beta_{0}+\beta_{1} \Delta E T+\beta_{2} \Delta N D V I+\beta_{3} \Delta L S T+\beta_{4} \Delta S M+\beta_{5} \Delta T W S A+\varepsilon
$$


where $\Delta Y$ is the variation of soil salinization index, $\triangle E T, \triangle N D V I, \triangle L S T, \triangle S M$, and $\Delta T W S A$ are the variation of each eco-hydrological parameter, and $\beta_{\mathrm{i}}$ are the sensitivity coefficients of soil salinization characteristic index to eco-hydrological parameters.

\section{Results}

\subsection{Spatial Patterns of Soil Salinization in Kashgar Region}

The spatial patterns of soil salinization in the Kashgar region of Xinjiang in 2000, 2010, and 2017 were generated by the human-computer interactive interpretation method, as shown in Figure 3. In this study, a total of 19 field survey sites with detailed salinized soil types for the years 2001, 2009, and 2017 were collected from the annual inventory dataset of the local water conservation bureau to best match the years of interpreted classification maps. A total of 715 pixels were then selected as samples based on field measured data, and $30 \%$ of them were used as the validation pixels to assess the accuracy of salinized soil classification. Due to the validation samples is insufficient, the accuracy of classification maps from three years was evaluated as a whole by constructing an error matrix [17], and the error matrix showed that overall accuracy was $90.4 \%$, with a kappa coefficient of 0.914, for all seven types of classification maps of three years shown in Figure 3. These results suggest that the accuracy of the human-computer interactive interpretation method was satisfactory for detecting soil salinization.
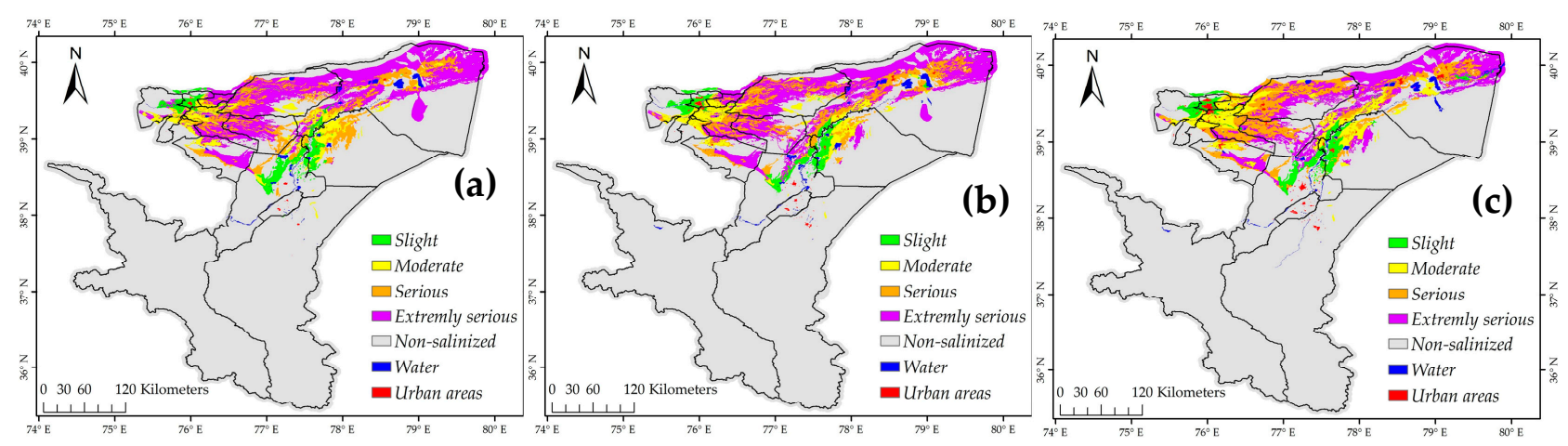

Figure 3. Distribution of soil salinization in the Kashgar region in 2000 (a), 2010 (b), and 2017 (c).

It can be seen from Figure 3 that the salinized soil in the Kashgar region was mainly on the plain and concentrated in the two irrigation areas of the Yarkand River Basin and Kashgar River Basin. There was almost no salinized soil in the Tashkurgan Taji autonomous county, Zepu county, and Yecheng county, which were located at the upper and middle reaches of the Yarkant River Basin. Slightly and moderately salinized soils were mainly distributed in Shufu county, Shule county, and Kashgar city where Kashgar River flows through, and in Shache county and Maigaiti county where Yeerqiang River flows through. Severely and extremely severely salinized soils were mainly distributed in the Yingjisha county, Jiashi county, Yuepuhu county, and Bachu county.

The severity of salinization changed along the longitudinal profile of rivers, and the severity was gradually getting worse from the upstream to the downstream in the Yeerqiang River and Kashgar River. Meanwhile, the severity of salinization also changed with the distance from the main river channel, soils near the main channel were mildly salinized, and the severity of salinization was worse for soils farther away from the main channel. The spatial pattern of soil salinization change was also closely related to the position of rivers when comparing the soil salinization maps for three different periods. The slightly and moderately salinized soil expanded to the downstream area, and the area of extremely severely salinized soil decreased during the study period. 


\subsection{Spatiotemporal Variations of Soil Salinization in the Kashgar Region}

\subsubsection{Area Variation of Different Salinized Soil Types}

The area of different salinized soil types and other land types in different periods were obtained based on classified statistics of the salinized soil in 2000, 2010, and 2017. Then, we constructed the soil salinization transfer matrix between 2000-2010 and 2010-2017, as shown in Tables 3 and 4. The areas of different grades of salinized soil are shown in Figure 4a. Decreased area of a specific grade of salinized soil was calculated by summing areas of the regions converting from itself into others (red bar), and the total area of regions converting from others into itself is increased area (green bar), as shown in the Figure $4 b, c$.

It can be seen that the area of land with severer salinization grades is larger than those with slighter grades. In 2000, the area of salinized land in Kashgar was $2.65 \times 10^{4} \mathrm{~km}^{2}$, which decreased to $2.5 \times 10^{4} \mathrm{~km}^{2}$ in 2010 and continued to drop to $2.45 \times 10^{4} \mathrm{~km}^{2}$ in 2017 (Figure 4a). From 2000 to 2010, the net decreased area of salinized soil is $1.55 \times 10^{3} \mathrm{~km}^{2}$, and the relative change rate of the area was $-6.13 \%$. From 2010 to 2017, the net decreased area of salinized soil was $398.4 \mathrm{~km}^{2}$, and the relative change rate of the area was $-1.75 \%$. It can be concluded that the soil salinization in this region was becoming less severe with the decreasing of the salinized soil area but with a slower decreasing rate in the recent years.

The temporal change trend of the area of salinized soil was divergent for different soil salinization grades. The area of slightly, moderately, and severely salinized soil showed an increasing trend from 2000 to 2017, while the area of extremely severely salinized soil significantly decreased from $1.4 \times 10^{4} \mathrm{~km}^{2}$ in 2000 to $1.0 \times 10^{4} \mathrm{~km}^{2}$ in 2017, with a largest net decrease rate of $-30 \%$ among four grades of salinized soil (Figure $4 b, c$ ), indicating the obvious improvement of extremely severely salinized soil in the Kashgar. However, although the area of deteriorating land with extremely severer soil salinization grades substantially decreased, the area with slighter soil salinization grades was notably increasing (Figure 4c), which deserves the attention of local governments and policymakers.

Table 3. Transfer matrix of salinized land from 2000 to $2010\left(\mathrm{~km}^{2}\right)$.

\begin{tabular}{cccccccc}
\hline \multirow{2}{2010}{$\mathbf{2 0 0 0}$} & Slight & Moderate & Severe & Extremely Severe & Non-Salinized & Water & Urban Area \\
\hline Slight & 1646.92 & 108.46 & 79.54 & 230.94 & 213.58 & 23.64 & 40.73 \\
\hline Moderate & 347.76 & 2308.69 & 544.64 & 205.73 & 169.49 & 28.36 \\
\hline Severe & 44.27 & 699.51 & 3826.26 & 1082.92 & 399.24 & 14.79 & 45.00 \\
\hline Extremely Severe & 106.45 & 348.89 & 1723.42 & $11,601.19$ & 644.47 & 47.80 & 5.12 \\
\hline Non-salinized & 0.00 & 0.00 & 0.00 & 0.00 & $99,909.98$ & 230.08 & 58.07 \\
\hline Water & 8.13 & 26.73 & 10.79 & 40.58 & 97.79 & 636.49 & 0.37 \\
\hline Urban area & 2.98 & 2.29 & 3.04 & 1.21 & 1.84 & 0.08 & 95.71 \\
\hline
\end{tabular}

Table 4. Transfer matrix of salinized land from 2010 to $2017\left(\mathrm{~km}^{2}\right)$.

\begin{tabular}{|c|c|c|c|c|c|c|c|}
\hline $2017 \quad 2010$ & Slight & Moderate & Severe & Extremely Severe & Non-Salinized & Water & Urban Area \\
\hline Slight & 1756.49 & 44.77 & 45.48 & 64.53 & 168.31 & 8.59 & 66.62 \\
\hline Moderate & 201.50 & 2443.89 & 264.65 & 205.38 & 279.75 & 35.22 & 61.39 \\
\hline Severe & 104.16 & 1243.43 & 4091.67 & 481.86 & 142.76 & 22.81 & 96.06 \\
\hline Extremely Severe & 301.55 & 540.78 & 2714.69 & 8981.15 & 449.20 & 124.96 & 39.73 \\
\hline Non-salinized & 130.43 & 119.38 & 247.36 & 352.28 & $10,0182.26$ & 236.05 & 87.18 \\
\hline Water & 36.27 & 27.79 & 58.32 & 59.93 & 188.12 & 609.27 & 0.76 \\
\hline Urban area & 0.00 & 0.00 & 0.00 & 0.00 & 0.90 & 0.03 & 258.05 \\
\hline
\end{tabular}



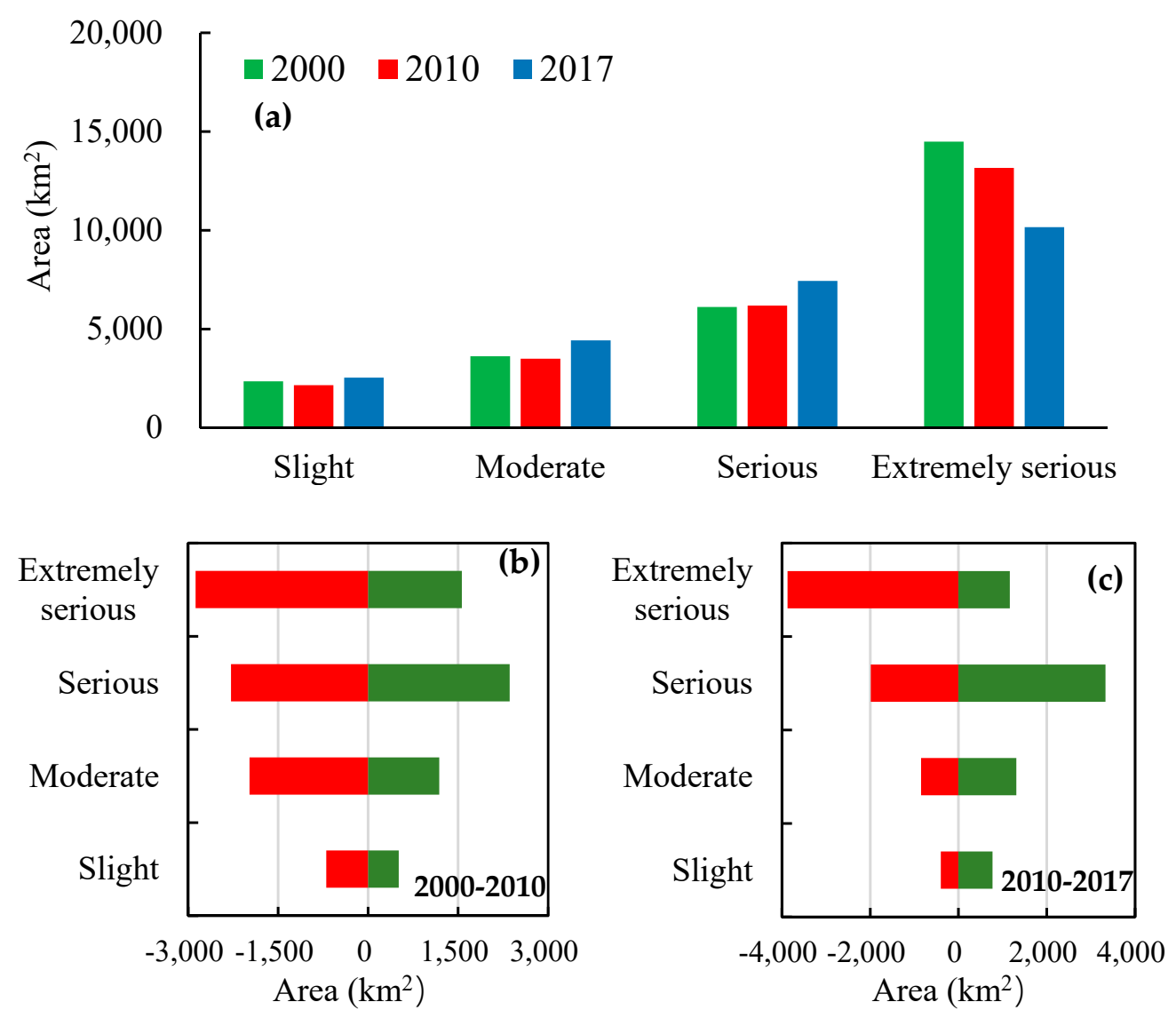

Figure 4. The area of different salinized soil grades in different periods (a) and the area variation of different salinized soil grades during 2000-2010 (b) and 2010-2017 (c).

Figure 5 shows the relative change of salinized soil area in different counties of the study area. From 2000 to 2010, the area of salinized soil in all counties decreased in varying degrees, and the area of salinized soil in Zepu county where is a non-oasis region decreased the most, with a relative change rate of $100 \%$. The decrease degree of salinized soil area in Shache county was the largest in all plain oasis regions, whose relative change rate was $-12.59 \%$. From 2010 to 2017, the originally improved soil salinization in the Yuepuhu county, Yingjisha county, Yecheng county, Shache county, and Maigaiti county during 2000 to 2010 rebounded, emerging a trend of deterioration. Among these, the area of salinized soil in the Yecheng county in the non-oasis area increased the most, with a relative change rate of $42.3 \%$, followed by the Yuepuhu county in the oasis area with a relative change rate of $6.91 \%$. On the contrary, the area of salinized soil in Kashgar city decreased the most in all counties with a relative change rate of $-11.1 \%$. 

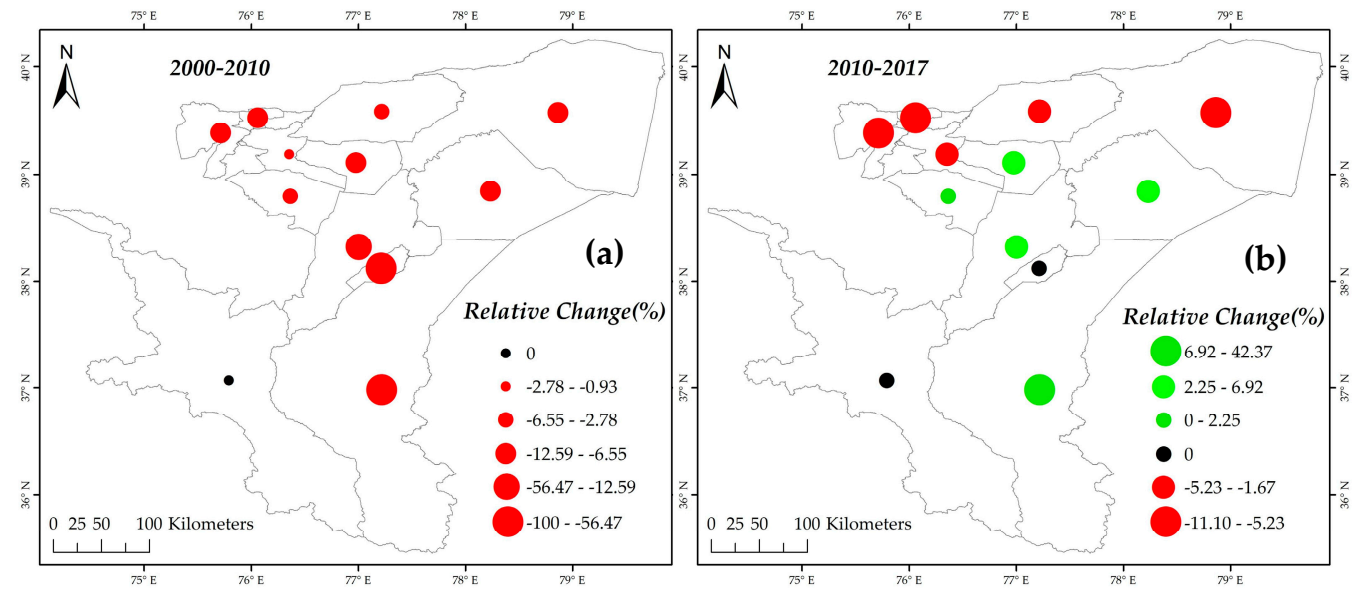

Figure 5. Relative change rate of salinized soil area in different counties of the Kashgar region during 2000 to 2010 (a) and 2010 to 2017 (b).

\subsubsection{Variation of Soil Salinization Severity}

Based on the transfer matrix (Tables 3 and 4), we analyzed the relative change rate of soil salinization severity using Equation (4) (Figure 6). It can be seen from this figure that there are significant differences between the relative change rate of soil salinization severity and that of the salinized soil area. The relative change of soil salinization severity in the Kashgar region was $-6.6 \%$ from 2000 to 2010, with that during 2010 to 2017 being $-7.55 \%$, indicating the increase of salinization alleviation range. From 2000 to 2010, although the total area of salinized soil in the Shache county decreased, the increased area of extremely severely salinized soil in this region was quite large; consequently, the regional soil salinization severity actually became worse, which can be seen from the relative change rate of $15.78 \%$. For the latter period, the area of salinized soil in the Maigaiti county increased, but due to the significant reduction of moderately and extremely severely salinized soil area, the regional soil salinization severity became milder, and that can also be identified from the relative change rate of $-27.59 \%$. Consequently, our study successfully verified the application of the newly established salinization severity index in reflecting the severity of soil salinization and provided a feasible scientific method for the objective detection of soil salinization spatiotemporal dynamics.
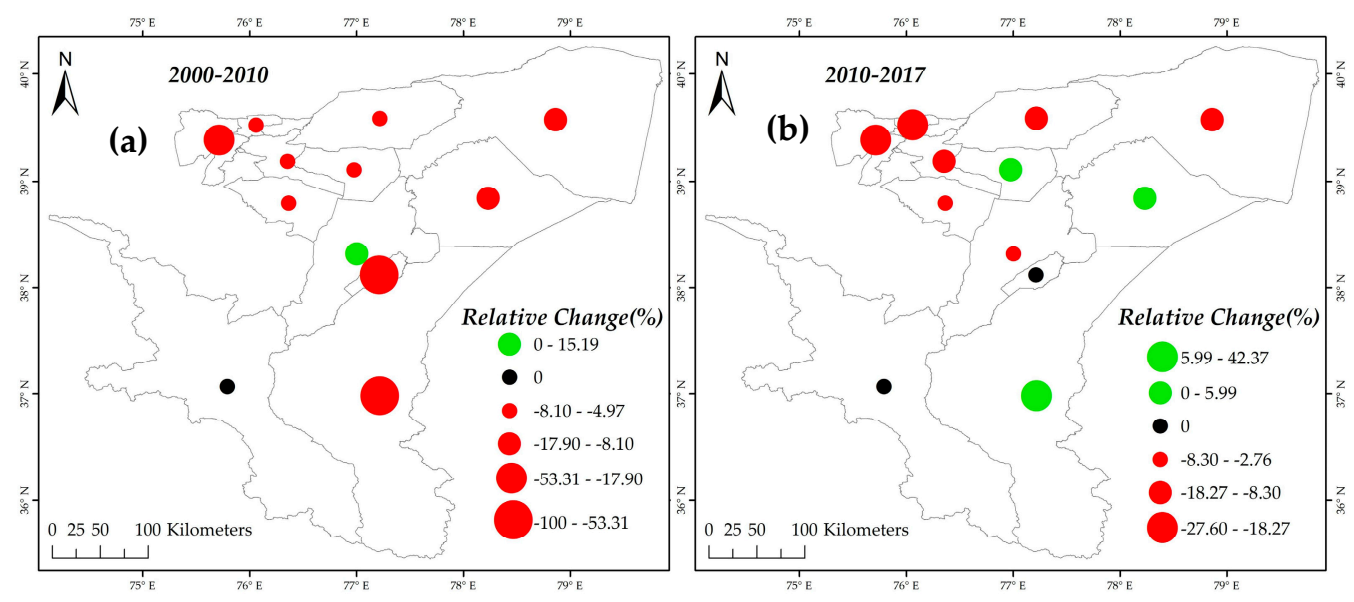

Figure 6. Relative change rate of soil salinization severity in different counties of the Kashgar region during 2000 to 2010 (a) and 2010 to 2017 (b). 


\subsubsection{Spatiotemporal Distribution of the Main Change Types of Salinized Soil}

In order to explore the variation characteristics of soil salinization, we analyzed the change types of salinized soil in different periods based on the transfer matrix. Our analysis showed that there are 38 change types of salinized soil, and we highlighted the main change types in different periods by calculating the importance index of soil salinization change (Figures 7 and 8). From 2000 to 2010, the improved area of salinized soil reached $4916.7 \mathrm{~km}^{2}$, scattered in the irrigation areas of Bachu county, Yuepuhu county, and Jiashi county, of which $644.5 \mathrm{~km}^{2}$ was directly improved from extremely severely salinized soil to non-salinized soil. The degraded area of salinized soil was $2338.46 \mathrm{~km}^{2}$, which was mainly distributed in the irrigated regions of Maigaiti county, Bachu county, and Yuepuhu county (Figure 8a). The area of non-salinized soil degraded to salinized soil was $95.7 \mathrm{~km}^{2}$. During the study period, the dominant change type was the transformation from extremely severely salinized soil to severely salinized soil, accounting for $22.52 \%$ of the total area of all change types, followed by the transformation from severely salinized soil to extremely severely salinized soil (Figure 7a). From 2010 to 2017, the improved area of salinized soil reached $6601.51 \mathrm{~km}^{2}$, which were mainly distributed in the irrigated regions of Bachu county, Yuepuhu county, Jiashi county, and Shufu county. The area of improvement from extremely severely salinized soil to non-salinized soil was $449.2 \mathrm{~km}^{2}$. The degraded area of salinized soil reached $2138.73 \mathrm{~km}^{2}$, which were mainly distributed in Bachu county and Maigaiti county, of which $1032.1 \mathrm{~km}^{2}$ were converted from non- salinized soil to salinized soil (Figure $8 \mathrm{~b}$ ). In this period, the dominant change type was still the conversion from extremely severely salinized soil to severely salinized soil, accounting for $29.34 \%$ of the total area of all change types, followed by the transformation from severely salinized soil to moderately salinized soil, accounting for $13.44 \%$ (Figure $7 \mathrm{~b}$ ). Although the area of other change types was relatively small, the significant degradation trend of non-salinized soil to slight salinized soil deserves more attention. Our results suggest that necessary irrigation control measures must be taken to protect these lands from further soil salinizing.
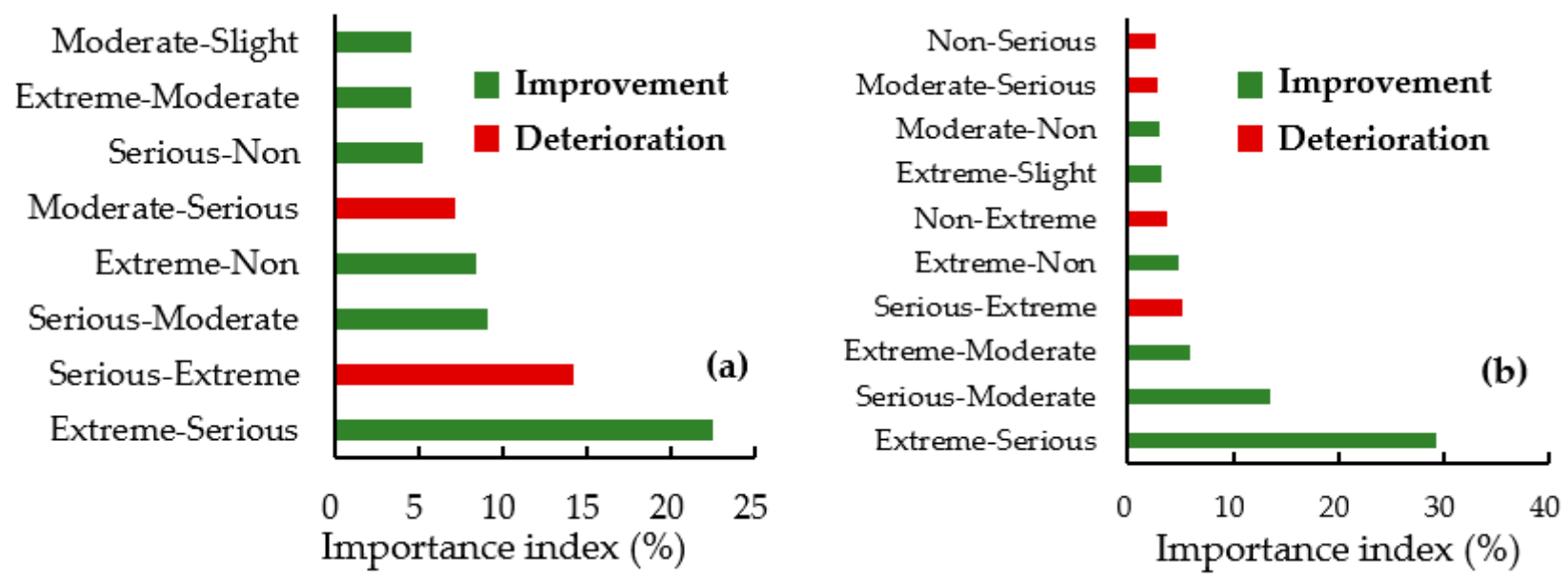

Figure 7. The importance index of different salinized soil types during 2000 to 2010 (a) and 2010 to 2017 (b). 


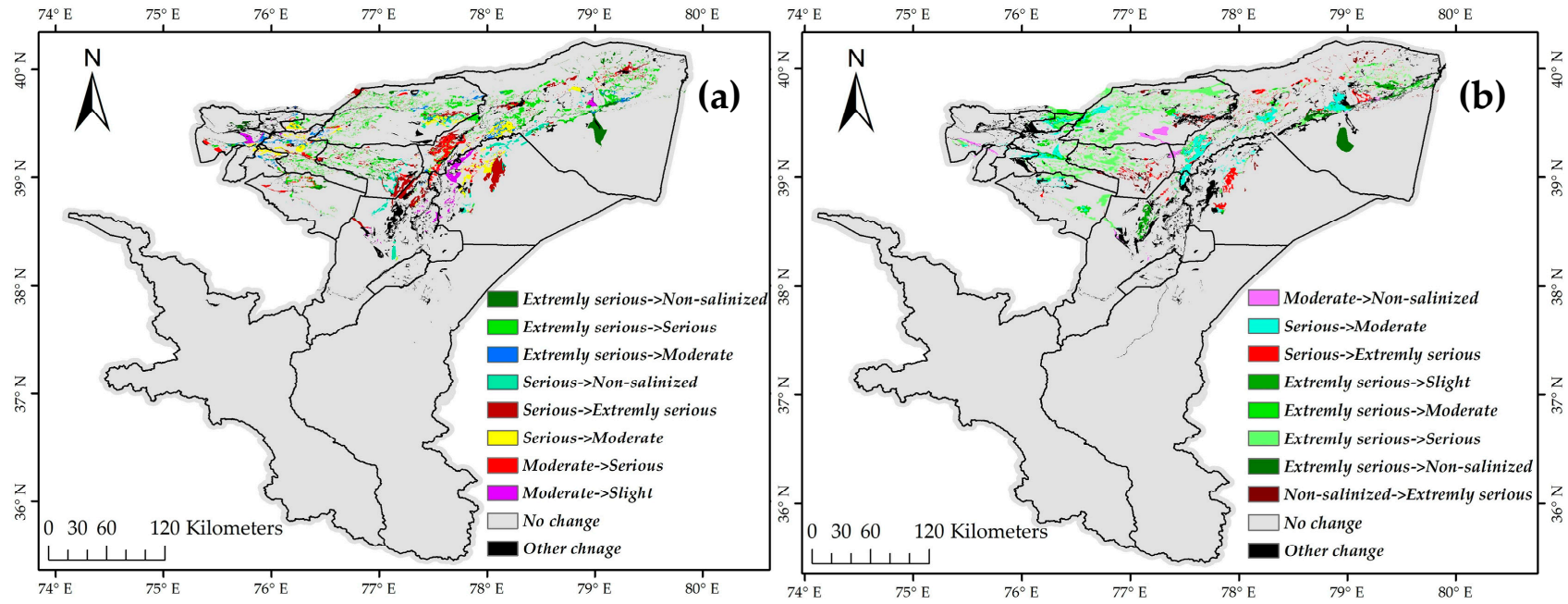

Figure 8. Spatial distribution of dominant change types of salinized soil in 2000-2010 (a) and 2010-2017 (b).

\subsection{Spatiotemporal Variations of Eco-Hydrological Parameters in Kashgar Region}

The significant increase of NDVI mainly concentrated in the Kashgar River Basin and Yeerqiang River Basin, covering the Zepu county, the northeast of Shache county, the west of Maigaiti county, the middle of Bachu county, the middle of Jiashi county, Kashi city, the east of Shufu county, Shule county, and the middle of Yuepuhu county, with the corresponding annual growth rate of more than $0.25 \%$ per year. The area with significantly decreased NDVI was mainly located in the Kunlun mountain in the south of the Kashgar region, covering the south of the Tashkurgan Tajik autonomous county and the south of Yecheng county (Figure 9a). The overall land surface temperature showed an increasing trend, and the temperature increase in the northern counties of the Kashgar region was statistically significant, and the largest increase trend (above $0.2{ }^{\circ} \mathrm{C} / \mathrm{a}$ ) occurred in the Maigaiti county and Bachu county (Figure $9 \mathrm{~b}$ ). Our results showed that the soil moisture in the Kashgar region showed an overall increasing trend, with a significant increasing trend mainly distributed in the northeast and southwest of the Bachu county, the southeast of Jiashi county, the west of Shule county, Yuepuhu county, the west of Yingjisha county, the middle and west of Maigaiti county, Shache county, Zepu county, the north-central part of Yecheng county, and the south-central part of Tashikorgan Tajik autonomous county with an increasing trend of more than $2 \mathrm{~mm} / \mathrm{a}$. The decreasing trend of soil moisture was mainly located in Shufu county, Kashgar city, and the southeast of Yecheng county; however, the trends were not significant (Figure 9c). The evapotranspiration in the Kashgar region showed an overall increasing trend, with significant growth trend mainly located in the Jiashi county, Shule county, Shufu county, Kashgar city, Yuepuhu county, Yingjisha county, central Shache county, most of Zepu county, Yecheng county, and Tashkurgan Tajik autonomous county, with a corresponding increasing trend of more than $2.5 \mathrm{~mm} / \mathrm{a}$ (Figure 9d). The terrestrial water storage anomaly in the Kashgar region showed a decreasing trend; however, the decreasing trends were not significant in most areas, and the regions with significant decreasing trends were mainly located in the Jiashi county and the central and eastern part of the Bachu county (Figure 9e). 

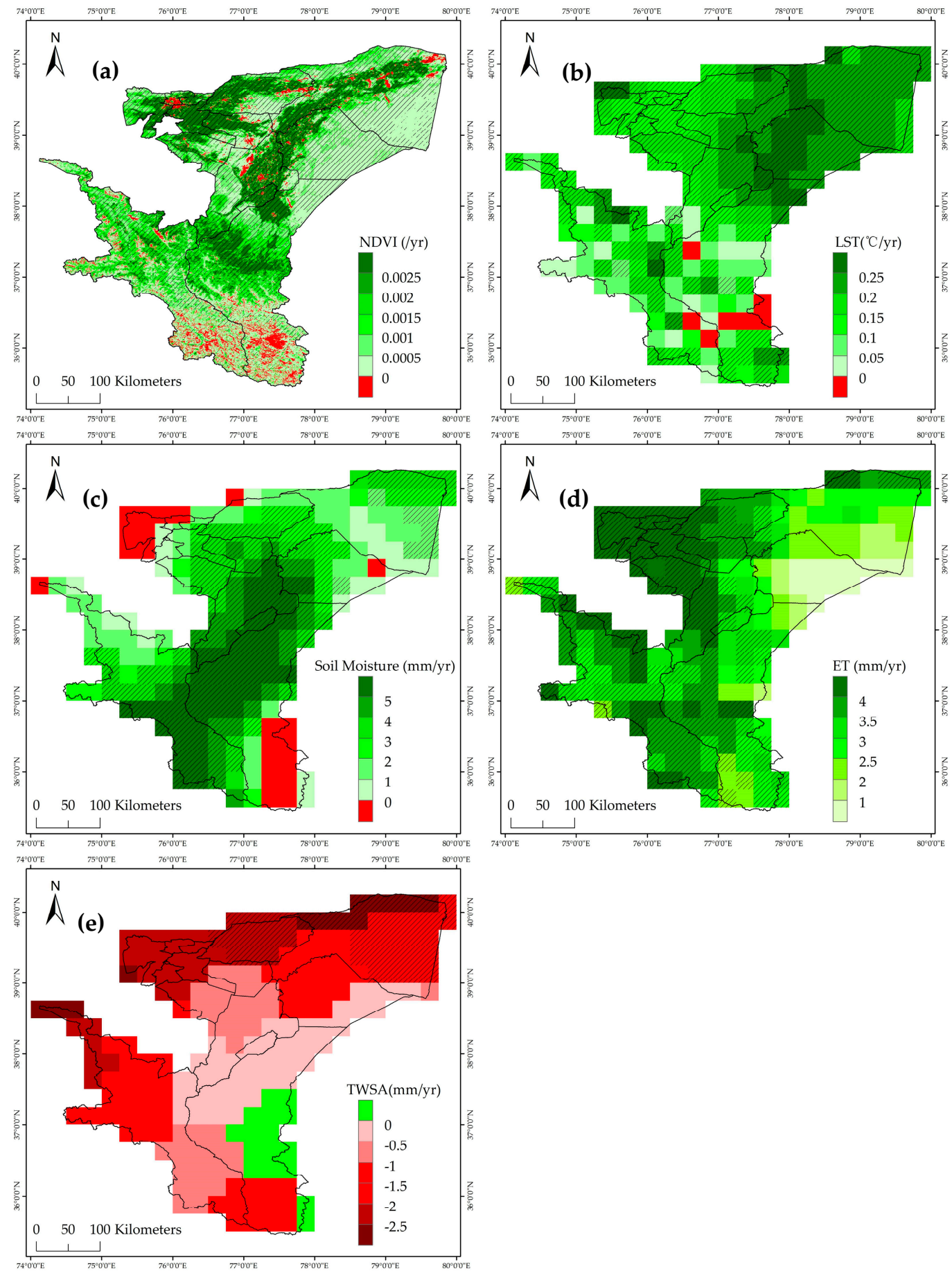

Figure 9. The spatial and temporal variation patterns of eco-hydrological parameters in the study area, normalized difference vegetation index (NDVI) (a), land surface temperature (LST) (b), soil moisture $(\mathrm{SM})(\mathbf{c})$, evapotranspiration (ET) (d), and total water storage anomalies (TWSA) (e).

\subsection{Responses of Soil Salinization to Key Eco-Hydrological Parameters}

In this study, we divided the salinized soil area, salinization severity, and eco-hydrological parameters into each $0.25^{\circ} \times 0.25^{\circ}$ grids to match the resolutions of all the eco-hydrological parameters. We further carried out the univariate linear regression analysis between the variation of salinized soil area or salinization severity and each eco-hydrological parameter, respectively (Figure 10). It can be seen that the linear regression relationships among the variation of all eco-hydrological parameters and that of salinized soil area were not significant, while that between NDVI, ET, and LST and salinization severity were significant $(p<0.01)$, 
in which ET showed the strongest explanation ability for the variation of soil salinization severity (Figure 10a-e). We highlighted the best eco-hydrological parameters for simulating the variation of salinization severity as ET and NDVI using the multiple linear stepwise regression analysis and then constructed a multiple linear regression model as shown in Equation (8), with adjusted $R^{2}$ and root mean square error (RMSE)being 0.43 and 0.184 , respectively. The statistical analysis using the F-test showed that the regressed equation was statistically significant (Figure 10f).

$$
\Delta S=-0.004 \times \Delta E T-2.971 \times \Delta N V D I+0.236(p<0.001)
$$
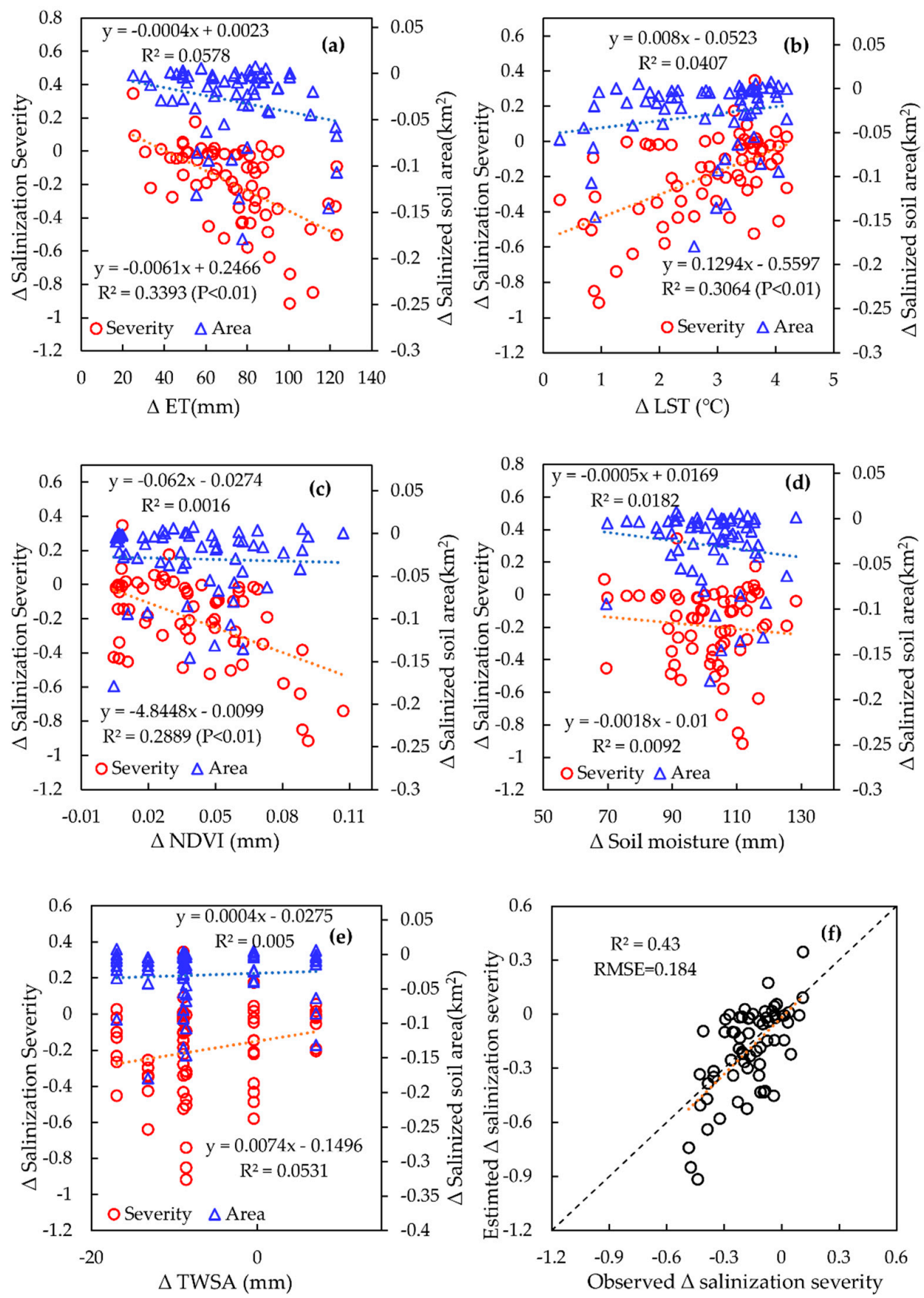

Figure 10. Linear relationships between the variations of soil salinization indicators (salinization severity and salinized soil area) and eco-hydrological parameters. (a) ET, (b) LST, (c) NDVI, (d) SM, (e) TWSA, (f) accuracy validation of the multiple linear regression model. 


\section{Discussion}

A large amount of salt accumulates along the surface runoff or underground runoff to the alluvial fan plain zone that has poor drainage from the exposed tertiary stratum around the basin margin where contains a lot of salt and gypsum, resulting in the increase of the salt content in surface water, groundwater, and soil water in some regions [48], which provided abundant salt material for soil salinization. Kashgar region is located in the temperate continental arid climate zone with abundant light and heat resources, less precipitation, and large evaporation. The temperature here showed large spatial variability and the sunlight time is relatively long. The weather in summer is hot and dry, with that in winter being cold and dry. The dry climate provides dynamic conditions for the vertical upward movement of soil water and salt $[24,25,49]$. The salt dissolved in phreatic water moves upward from the soil capillary with the evaporation of soil water and finally accumulates in the soil surface. In plain areas, the groundwater level is relatively shallow, which is more prone to accumulate salt in soil and form salinized land [27,48].

The two oases in Kashgar are important agricultural production areas in Xinjiang Uygur autonomous region. Population is an important factor reflecting the pressure of human activity on natural resources. According to the statistics of national population census, the population of the Kashgar region has increased by 1.37 times (or a total increase of 1.25 million) from 3.37 million in 2000 to 4.62 million in 2019, with an increased rate of $7.35 \times 10^{4}$ people per year (Figure 11). With the rapid growth of population, the per capita cultivated land, per capita food production, and per capita agricultural output value decreased. In the past two decades, with the advocacy and encouragement of the local government, most ethnic minorities in Xinjiang have begun to settle down in the form of semi pastoral and semi-agricultural life, which has increased the regional demand for agricultural land [50]. Due to the government's adjustment of the local industrial structure that encourages vigorous development of diversified management and commodity production, which promote the farm product price, resulting in the enhancement of farmers' enthusiasm for agricultural practices. Consequently, farmers expanded the cultivated land area by extensively reclaiming wasteland to increase the crop yield [50,51], which substantially promoted the local GDP (Figure 11).

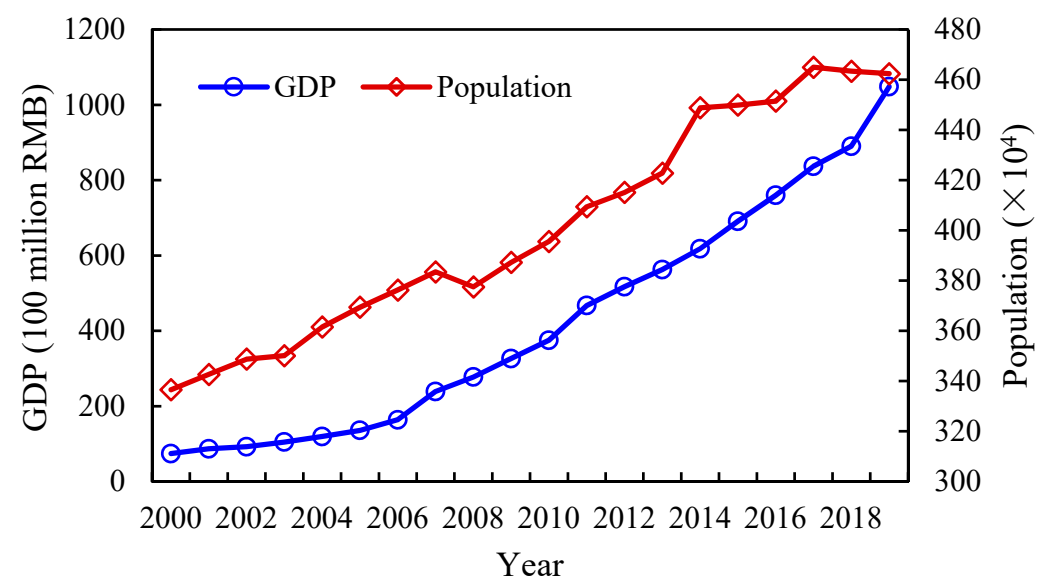

Figure 11. Gross domestic product (GDP) and population in Kashgar region from 2000 to 2019.

Driven by the increase in population and the development of the local economy, a large number of reserved areas were reclaimed and planted with crops, which led to significant growth of vegetation coverage in the oasis area (Figure 9a). The increase of vegetation in this arid region resulted in the significantly increasing evapotranspiration significantly increased (Figure 9d), which may intensify soil salinization in this region. At the same time, plant roots can change the soil's physical properties and promote soil desalination $[49,50]$. It can be clearly inferred from Figure 10 that the vegetation increasing in this area mainly played a positive role in improving salinized soil. Although 
evapotranspiration significantly increased in the study area, it was mainly due to the increase of vegetation transpiration rather than the aggravation of soil evaporation; hence, the increased evapotranspiration did not aggravate the soil salinization. At the same time, the increase of latent heat led to a significant decrease in surface temperature and soil evaporation. Consequently, the increase of NDVI, evapotranspiration, and decrease of LST jointly played a positive role in alleviating soil salinization.

Soil moisture in the oasis area showed an increasing trend, while the TWSA showed a slight decrease trend (Figure 9c,e), indicating the groundwater was exploited as the main source for irrigation here, which could have contributed to the alleviation of soil salinization $[27,51]$. However, unreasonable irrigation methods could also cause the accumulation of water in the irrigation area, resulting in the rise of groundwater level of some wasteland around or inside the irrigation area. Severe soil evaporation can also lead to the accumulation of soil salt $[31,50,51]$. For the newly reclaimed farmlands, soil salinization usually tends to be worse, mainly due to the lack of scientific and reasonable irrigation systems. As shown in Figures 7 and 8, the newly reclaimed farmlands in the oasis marginal area showed a trend of transformation from non-salinized soil to salinized soil, indicating that some strict irrigation control measures should be needed to protect these lands from further salinizing.

There are still some uncertainties from different sources in this study. Uncertainties from the data sources might have been the dominant factors. Due to field sampling and laboratory measurement of soil salt content are time-consuming and laborious works in a large area, a small number of measurement sites were collected in this study, which might affect the accuracy of validation on salinized soil maps to some extent. Therefore, new rapid field survey methods, such as electromagnetic induction, could be used in the future to obtain more field measured datasets. In addition, the resolution of the remote sensing images used to extract soil salinization information is only $30 \times 30 \mathrm{~m}$, and 18 remote sensing images are needed to cover the whole study area for each period. The temporal differences among images in different regions might have introduced some uncertainties during the interpretation of salinized land. Meanwhile, high vegetation coverage makes it difficult to avoid interpretation bias. Moreover, the eco-hydrological remote sensing products used in this study are global-scale products with coarse spatial resolution, and there may be some bias in these products when using them in the specific local region [52]. Thus, we integrated different products to reduce the impact of bias from the eco-hydrological products on the statistical analysis. In this study, we only extracted the soil salinization map for three specific years; thus, the study only reflected the dynamic changes of soil salinization in 2000 to 2010 and 2010 to 2017 but failed to effectively reflect the continuous annual changes of soil salinization during 2000 to 2017. Future researches can further improve the spatial and temporal detection accuracy of soil salinization. In addition, it is necessary to deeply explore the multi-scale influencing mechanisms of human activities on the spatiotemporal evolution of soil salinization to propose a suitable strategy for the restoration of soil salinization [53,54], and more databases related to human activities, such as the information of irrigation measures and irrigation systems can be adopted in future studies.

\section{Conclusions}

The investigation of the spatiotemporal variations of soil salinization is necessary for understanding the mechanisms that have caused soil salinization. In this study, the spatial distributions of soil salinization classified as five different grades were extracted using the Landsat remote sensing data in the Kashgar region for three different time periods (i.e., 2000, 2010, and 2017), and the spatial characteristics of soil salinization and their temporal evolutions were investigated. Then we extended our work by quantifying the response mechanisms of soil salinization to eco-hydrological parameters and clarifying the main driving factors of soil salinization. The main conclusions are as follows: 
(1) The area of land with severer soil salinization grades are larger than those with slighter grades. The relative change rate of salinization area was $-6.13 \%$ from 2000 to 2010 and $-1.75 \%$ from 2010 to 2017. The area of slightly, moderately, and severely salinized soil increased from 2000 to 2017, while that of extremely severely salinized soil decreased significantly. The transformation from extremely severe salinized soil to the severe ones during the two periods dominated the transformation of soil salinization in the study area, accounting for $22.52 \%$ and $29.34 \%$ of all change types, respectively.

(2) The relative change of salinization severity index was $-6.6 \%$ from 2000 to 2010 and $-7.55 \%$ from 2010 to 2017 . The remediation speed of soil salinization showed an increasing trend, indicating that the soil salinization in the Kashgar area was generally getting better. The significant linear relationships between the variations of salinization severity and ET and NDVI make these two indices a tool to effectively explain the dynamics of soil salinization severity.

(3) The expansion of cultivated land driven by population growth and economic development are the dominant factors for the evolution of soil salinization. Although the increase of vegetation cover in the oasis area led to a significant increase in evapotranspiration, it still played a positive role in alleviating soil salinization in this region. Hydraulic connectivity of soil was improved through a dramatic change of soil structure driven by root system growth of vegetation; therefore, soil salt content could be reduced by salt leaching during frequent irrigation. However, unreasonable irrigation practices have led to the transformation from non-salinized soil to salinized soil for the newly reclaimed farmland after 2010, indicating that scientific irrigation measures cannot be ignored to prevent the soil from salinizing.

Author Contributions: Conceptualization, X.D., B.W.; methodology, X.D., Z.W.; investigation, B.W., G.Q.; resources, B.W., G.Q.; manuscript writing, B.W., Z.W.; supervision, X.D. All authors have read and agreed to the published version of the manuscript.

Funding: This work was financially supported by the National Natural Science Foundation of China (41701509, 51779099), Special Research Fund of the YRIHR (HKY-JBYW-2020-09).

Data Availability Statement: Some data used during the study are available from the corresponding author by request (email: xinguangdong@163.com (X.D.)).

Acknowledgments: We thank the reviewers for their useful comments and suggestions. We thank the Xinjiang Agricultural University for its assistance with materials and instruments.

Conflicts of Interest: The authors declare no conflict of interest.

\section{References}

1. Szabolcs, I. Salinization of soil and water and its relation to desertification. Desertif. Control Bull. 1992, $21,32-37$.

2. Schofield, R.V.; Kirkby, M.J. Application of salinization indicators and initial development of potential global soil salinization scenario under climatic change. Glob. Biogeochem. Cycle 2003, 17, 1078. [CrossRef]

3. Das, R.S.; Rahman, M.; Sufian, N.P.; Rahman, S.M.A.; Siddique, M.A.M. Assessment of soil salinity in the accreted and nonaccreted land and its implication on the agricultural aspects of the Noakhali coastal region, Bangladesh. Heliyon 2020, 6, e04926. [CrossRef] [PubMed]

4. Sahab, S.; Suhani, I.; Srivastava, V.; Chauhan, P.S.; Prasad, V. Potential risk assessment of soil salinity to agroecosystem sustainability: Current status and management strategies. Sci. Total Environ. 2020, 764, 144-164.

5. Wei, Y.; Ding, J.; Yang, S.; Wang, F.; Wang, C. Soil salinity prediction based on scale-dependent relationships with environmental variables by discrete wavelet transform in the Tarim Basin. Catena 2021, 196, 104939. [CrossRef]

6. Li, J.; Pu, L.; Han, M.; Zhu, M.; Runsen, Z.; Xiang, Y. Soil salinization research in China: Advances and prospects. J. Geogr. Sci. 2014, 24, 943-960. [CrossRef]

7. Qiao, M. Soil Salinization in Xinjiang Irrigation Area and Its Governance Model; Xinjiang Science and Technology Press: Urumqi, China, 2008.

8. Li, L.; Sun, G.; Lu, H.; Lu, H.; Shi, H. Spatiotemporal changes and driving forces of ecological vulnerability in Kashi. Reg. Arid Land Geogr. 2021, 44, 277-288.

9. Rashid, K.; Jasur, M.; Jilili, A.; Bakhtiyor, K. Challenges for the sustainable use of water and land resources under a changing climate and increasing salinization in the Jizzakh irrigation zone of Uzbekistan. J. Arid Land 2020, 12, 92-105. 
10. Afrasinei, G.; Melis, M.; Arras, C.; Pistis, M.; Buttau, C.; Ghiglieri, G. Spatiotemporal and spectral analysis of sand encroachment dynamics in southern Tunisia. Eur. J. Remote Sens. 2018, 51, 2018. [CrossRef]

11. Afrasinei, G.; Melis, M.; Buttau, C.; Bradd, J.; Arras, C.; Ghiglieri, G. Assessment of remote sensing-based classification methods for change detection of salt-affected areas (Biskra area, Algeria). J. Appl. Remote Sens. 2017, 11, 016025. [CrossRef]

12. El Harti, A.; Lhissou, R.; Chokmani, K.; Ouzemou, J.E.; Hassouna, M.; Bachaoui, E.M.; El Ghmari, A. Spatiotemporal monitoring of soil salinization in irrigated Tadla PlainMorocco using satellite spectral indices. Int. J. Appl. Earth Obs. 2016, 50, 64-73. [CrossRef]

13. Scudiero, E.; Skaggs, T.H.; Corwin, D.L. Comparative regional-scale soil salinity assessment with near-ground apparent electrical conductivity and remote sensing canopy reflectance. Ecol. Indic. 2016, 70, 276-284. [CrossRef]

14. Scudiero, E.; Skaggs, T.H.; Corwin, D.L. Regional-scale soil salinity assessment using Landsat ETM + canopy reflectance. Remote Sens. Environ. 2015, 169, 335-343. [CrossRef]

15. Gorji, T.; Yildirim, A.; Hamzehpour, N.; Tanik, A.; Sertel, E. Soil salinity analysis of Urmia Lake Basin using Landsat-8 OLI and Sentinel- 2A based spectral indices and electrical conductivity measurements. Ecol. Indic. 2020, 112, 106173. [CrossRef]

16. Kristen, W.; Elia, S.; El-Askary, H.M.; Skaggs, T.H.; Mohamed, A.; Corwin, D.L. Validating the use of MODIS time series for salinity assessment over agricultural soils in California, USA. Ecol. Indic. 2018, 93, 889-898.

17. Zhang, T.; Qi, J.; Gao, Y.; Ouyang, Z.; Zeng, S. Detecting soil salinity with MODIS time series VI data. Ecol. Indic. 2015, 52, 480-489. [CrossRef]

18. Rocha Neto, O.; Teixeira, A.; Leão, R.; Moreira, L.; Galvão, L. Hyperspectral Remote Sensing for Detecting Soil Salinization Using ProSpecTIR-VS Aerial Imagery and Sensor Simulation. Remote Sens. 2017, 9, 42. [CrossRef]

19. Ma, L.; Ma, F.; Li, J.; Gu, Q.; Yang, S. Characterizing and modeling regional-scale variations in soil salinity in the arid oasis of Tarim Basin, China. Geoderma 2017, 305, 1-11. [CrossRef]

20. Chervan, A.M.; Ustinova, A.M.; Tsyrybko, V.B. Spatiotemporal Changes of Soil Salinization in the Soligorsk Mining Region. Eurasian Soil Sci. 2019, 52, 998-1006. [CrossRef]

21. Hamzehpour, N.; Bogaert, P. Improved spatiotemporal monitoring of soil salinity using filtered kriging with measurement errors: An application to the West Urmia Lake, Iran. Geoderma 2017, 295, 22-33. [CrossRef]

22. Su, Y.; Li, T.; Cheng, S.; Wang, X. Spatial distribution exploration and driving factor identification for soil salinisation based on geodetector models in coastal area. Ecol. Eng. 2020, 156, 105961. [CrossRef]

23. Zewdu, S.; Suryabhagavan, K.V.; Balakrishnan, M. Geo-spatial approach for soil salinity mapping in Sego Irrigation Farm, South Ethiopia. J. Saudi Soc. Agric. Sci. 2015, 16, 16-24. [CrossRef]

24. Niñerola, V.B.; Navarro-Pedreño, J.; Lucas, I.G.; Pastor, I.M.; Vidal, M.M.J. Geostatistical assessment of soil salinity and cropping systems used as soil phytoremediation strategy. J. Geochem. Explor. 2016, 174, 53-58. [CrossRef]

25. Gebremeskel, G.; Gebremicael, T.G.; Kifle, M.; Meresa, E.; Gebremedhin, T.; Girmay, A. Salinization pattern and its spatial distribution in the irrigated agriculture of Northern Ethiopia: An integrated approach of quantitative and spatial analysis. Agric. Water Manag. 2018, 206, 147-157. [CrossRef]

26. Barros, R.; Isidoro, D.; Aragüés, R. Three study decades on irrigation performance and salt concentrations and loads in the irrigation return flows of La Violada irrigation districtSpain. Agric. Ecosyst. Environ. 2012, 151, 44-52. [CrossRef]

27. Zhang, H.; Niu, L.; Hao, J.; Bao, R.; Zhang, Y.; Xing, X. Effect of Micro-topography and Groundwater Depth on Soil Potential Salinization in Heilonggang Basin. Bull. Soil Water Conserv. 2018, 38, 83-90.

28. Daliakopoulos, I.N.; Tsanis, I.K.; Koutroulis, A.; Kourgialas, N.N.; Varouchakis, A.E.; Karatzas, G.P.; Ritsema, C.J. The threat of soil salinity: A European scale review. Sci. Total Environ. 2016, 573, 727-739. [CrossRef] [PubMed]

29. Wang, Y.; Deng, C.; Liu, Y.; Niu, Z.; Li, Y. Identifying change in spatial accumulation of soil salinity in an inland river watershed, China. Sci. Total Environ. 2018, 621, 177-185. [CrossRef] [PubMed]

30. Zheng, S.; Loureno, S.D.N.; Cleall, P.J.; May Chui, T.F.; Ng, A.K.Y.; Millis, S.W. Hydrologic behavior of model slopes with synthetic water repellent soils. J. Hydrol. 2017, 554, 582-599. [CrossRef]

31. Zewdu, S.; Suryabhagavan, K.V.; Balakrishnan, M. Land-use $\backslash /$ land-cover dynamics in Sego Irrigation Farm, southern Ethiopia: A comparison of temporal soil salinization using geospatial tools. J. Saudi Soc. Agric. Sci. 2014, 15, 91-97. [CrossRef]

32. He, B.; Ding, J.; Liu, B.; Wang, J. Spatiotemporal Variation of Soil Salinization in Weigan-Kuqa River Delta Oasis. Scien. Silvae Sin. 2019, 55, 185-196.

33. Landsat5 TM, Landsat 7 ETM+ and Landsat8 OLI Images. Available online: http:/ / earthexplorer.usgs.gov (accessed on 8 June 2020).

34. The Normalized Difference Vegetation Index (NDVI) and Land Surface Temperature (LST) MODIS Products. Available online: https:/ / search.earthdata.nasa.gov (accessed on 9 May 2020).

35. Gravity Recovery and Climate Experiment (GRACE) Mascon Products. Available online: https://podaac.jpl.nasa.gov / (accessed on 12 June 2020).

36. Global Land Data Assimilation System (GLDAS) Products. Available online: https://search.earthdata.nasa.gov (accessed on 23 September 2020).

37. Global Land Evaporation Amsterdam Model (GLEAM) Products. Available online: https://www.gleam.eu (accessed on 30 August 2020). 
38. Australian Commonwealth Scientific and Research Organization (CSIRO) PML_V2 Products. Available online: http://data.tpdc. ac.cn/zh-hans (accessed on 9 May 2020).

39. State Forestry Administration of People's Republic of China. Atlas of Desertification and Sandified Land in China; Science Press: Beijing, China, 2009.

40. Han, H.; Yang, C.; Song, J. Scenario Simulation and the Prediction of Land Use and Land Cover Change in Beijing, China Sustainability 2015, 7, 4260-4279. [CrossRef]

41. Luo, Y.; Yang, S.; Liu, X.; Liu, C.; Song, W.; Dong, G.; Zhao, H.; Lou, H. Land use change in the reach from Hekouzhen to Tongguan of the Yellow River during 1998-2010. Acta Geogr. Sin. 2014, 69, 42-53.

42. Kendall, M.G. A new measure of rank correlation. Biometrika 1938, 30, 81-93. [CrossRef]

43. Li, H.; Wang, S.; Bai, X.; Luo, W.; Tang, H.; Cao, Y.; Wu, L.; Chen, F.; Li, Q.; Zeng, C. Spatiotemporal distribution and national measurement of the global carbonate carbon sink. Sci. Total Environ. 2018, 643, 157-170. [CrossRef] [PubMed]

44. Li, H.; Wu, Y.; Chen, J.; Zhao, F.; Wang, F.; Sun, Y.; Zhang, G.; Qiu, L. Responses of soil organic carbon to climate change in the Qilian Mountains and its future projection. J. Hydrol. 2021, 596, 126110. [CrossRef]

45. Li, H.W.; Wang, S.J.; Bai, X.Y.; Cao, Y.; Wu, L.H. Spatiotemporal evolution of carbon sequestration of limestone weathering in China. Sci. China Earth Sci. 2019, 62, 974-991. [CrossRef]

46. Mann, H.B. Nonparametric Tests against Trend. Econometrica 1945, 13, 245-259. [CrossRef]

47. Wang, Z.; Yao, W.; Tang, Q.; Yang, E.; Kong, X.; Wang, L.; Xiao, P. Spatio-temporal change analysis of leaf area index in the Loess Plateau during 2000-2014. Sci. Soil Water Conserv. 2017, 15, 71-80.

48. Li, J.; Gao, M. Temporal and Spatial Characteristics of Salinization of Coastal Soils in the Yellow River Delta. Chin. J. Soil Sci. 2018, $49,1458-1465$.

49. Lai, N.; Li, X.; Turdi, A.; Ezezezi, M. Analysis of tempo-spatial dynamic change and the cause of soil salinization in the oasis of the lower reaches of Kaidu River Basin. J. Arid Land Resour. Environ. 2013, 27, 66-73.

50. Qiao, M.; Zhou, S.; Lu, L.; Yan, J.; Li, H. Temporal and spatial changes of soil salinization and improved countermeasures of Tarim Basin Irrigation District in recent 25 years. Arid Land Geogr. 2011, 34, 604-615.

51. Yan, Z.; Wang, X.; Gao, F.; Huang, Q.; Yuan, Z.; Zhuo, R. Monitoring analysis on spatio-temporal changes of the soil salinization in the upper stream of Tarim River. J. Arid Land Resour. Environ. 2010, 24, 105-110.

52. Sun, P.; Wu, Y.; Xiao, J.; Hui, J.; Hu, J.; Zhao, F.; Qiu, L.; Liu, S. Remote sensing and modeling fusion for investigating the ecosystem water-carbon coupling processes. Sci. Total Environ. 2019, 697, 134064. [CrossRef]

53. Li, J.; Pu, L.; Zhu, M.; Zhang, R. The Present Situation and Hot Issues in the Salt-affected Soil Research. Acta Geogr. Sin. 2012, 67, 1233-1245.

54. Wang, J.; Huang, X.; Zhong, T.; Chen, Z. Review on Sustainable Utilization of Salt-affected Land. Acta Geogr. Sin. 2011, 66, 673-684. 